\title{
Self-Catalytic Growth of Tin Oxide Nanowires by Chemical Vapor Deposition Process
}

\author{
Bongani S. Thabethe, ${ }^{1,2}$ Gerald F. Malgas,, David E. Motaung, \\ Thomas Malwela, ${ }^{1}$ and Christopher J. Arendse ${ }^{2}$ \\ ${ }^{1}$ DST/CSIR Nanotechnology Innovation Centre, National Centre for Nanostructured Materials, \\ Council for Scientific and Industrial Research, P.O. Box 395, Pretoria 0001, South Africa \\ ${ }^{2}$ Department of Physics, University of the Western Cape, Private Bag X17, Bellville 7535, South Africa
}

Correspondence should be addressed to Gerald F. Malgas; gmalgas@csir.co.za and David E. Motaung; dmotaung@csir.co.za

Received 20 February 2013; Accepted 10 June 2013

Academic Editor: Rakesh Joshi

Copyright (c) 2013 Bongani S. Thabethe et al. This is an open access article distributed under the Creative Commons Attribution License, which permits unrestricted use, distribution, and reproduction in any medium, provided the original work is properly cited.

We report on the synthesis of tin oxide $\left(\mathrm{SnO}_{2}\right)$ nanowires by a chemical vapor deposition (CVD) process. Commercially bought $\mathrm{SnO}$ nanopowders were vaporized at $1050^{\circ} \mathrm{C}$ for 30 minutes with argon gas continuously passing through the system. The assynthesized products were characterized using UV-visible absorption spectroscopy, X-ray diffraction (XRD), scanning electron microscopy (SEM), and high-resolution transmission electron microscopy (HRTEM). The band gap of the nanowires determined from UV-visible absorption was around $3.7 \mathrm{eV}$. The SEM micrographs revealed "wool-like" structure which contains nanoribbons and nanowires with liquid droplets at the tips. Nanowires typically have diameter in the range of 50-200 $\mathrm{nm}$ and length $10-100 \mu \mathrm{m}$. These nanowires followed the vapor-liquid-solid (VLS) growth mechanism.

\section{Introduction}

One-dimensional (1D) metal oxides semiconductor nanomaterials have attracted great interest as CO gas sensors due to their novel electronic and optical properties in nanodevices and because of their active sites to adsorb gas molecules and catalytic reactions [1-7]. These sensors play an essential role in the fields of industrial processing, environmental protection, and medical treatment. However, many problems need to be solved to further improve the selectivity, sensitivity, and stability of the sensors. Among them $\mathrm{SnO}_{2}$, an n-type semiconductor with a wide direct band gap energy of $3.6 \mathrm{eV}$, is a particular material of interest because of its unique electrical properties, optical properties, small size, high sensitivity, good chemical stability, high electron mobility, fast response, and recovery speed $[4,8-10]$. Tin oxide thin films find the best use in chemical sensors which are commercially available for detecting fuel gas, carbon monoxide, combustible gases, ammonia, water vapour, and numerous other gases and vapors [11].
Due to the enhanced surface-to-volume ratio of 1D structures, tin oxide nanowires have been shown to have excellent sensing performance which is comparable to or even better than the thin film sensors [12-14]. These structures with a high aspect ratio (i.e., size confinement in two coordinates) offer better crystallinity, higher integration density, and lower power consumption [15]. It has been reported by several authors that the performances of gas sensors can be enhanced by increasing the specific surface area by way of achieving nanoparticles $[16,17]$ and by incorporation of noble metals [18], such as platinum or gold. $\mathrm{SnO}_{2}$ nanowires have been synthesized by different methods, such as laser ablation [19], solution [20], template-based method [21], chemical vapor deposition [22], and thermal evaporation [23]. In the last year, a great effort has been put into understanding and controlling the growth process for the preparation of high quality quasi one-dimensional nanostructures. In this study, we report on the self-catalytic growth of $\mathrm{SnO}_{2}$ nanowires using a chemical vapor deposition process. The optical and structural 
properties of the as-grown nanowires at room temperature are also studied.

\section{Experimental Details}

Tin oxide nanowires were grown on a silicon substrate and at the end of the tube by a CVD process using about one gram of monotin oxide ( $\mathrm{SnO}$ ) (purity 90\%) at a growth temperature of $1050^{\circ} \mathrm{C}$. The $\mathrm{SnO}$ was placed into a quartz boat and inserted into the centre of a quartz tube (radius $=5 \mathrm{~cm}$, length $=20 \mathrm{~cm}$ ) at a distance of about $1-2 \mathrm{~cm}$ from the Si substrate. The furnace temperature was increased from room temperature $\left(25^{\circ} \mathrm{C}\right)$ to $1050^{\circ} \mathrm{C}$ for $30 \mathrm{~min}$. The annealing was made in an argon atmosphere at atmospheric pressure. After cooling down, a fluffy layer of deposition could be collected from inside the tube wall ends in the lower end temperature zone or on the Silicon substrate.

UV-visible absorption measurements were carried out on the $\mathrm{SnO}$ nanopowders and the $\mathrm{SnO}_{2}$ nanowires using a Perkin Elmer spectrophotometer in a range between 200 and $900 \mathrm{~nm}$. The morphology of the product was examined by field-emission scanning electron microscopy (Auriga Zeiss SEM) with a beam energy of $3 \mathrm{keV}$. The crystal structure of the as-synthesized product was analysed by X-ray diffraction (XRD) analysis using a Phillips X-ray diffractometer. A high-resolution transmission electron microscope (HRTEMJEOL-2000) was used to examine the internal structure of the as-synthesized product. The chemical compositions were determined using an energy dispersive X-ray spectrometer (EDS) attached to the HRTEM instrument.

\section{Results and Discussion}

The optical band gap of commercially bought $\mathrm{SnO}$ and $\mathrm{SnO}_{2}$ nanowires was investigated using the UV-visible absorption spectrometer. Figure 1 shows the UV-vis spectra of the commercially bought $\mathrm{SnO}$ powder and as-synthesized $\mathrm{SnO}_{2}$ nanowires at $1050^{\circ} \mathrm{C}$ for $30 \mathrm{~min}$ in argon gas. Both samples were dissolved in isopropanol for UV-vis analysis. A weak band edge absorption in the spectrum is observed around the $375 \mathrm{~nm}$ wavelength. The optical transition of $\mathrm{SnO}_{2}$ crystals is known to be a direct type [24], where the absorption coefficient $\alpha$ can be expressed as [25]

$$
(\alpha h v)^{2} \propto\left(h v-E_{g}\right),
$$

where $h \nu$ is the photon energy, $E_{g}$ is the apparent optical band gap, and $\alpha$ is the absorption coefficient. Plots of $(\alpha h \nu)^{2}$ versus $h v$ can be derived from the absorption data in Figure 1 as shown in the inset. Therefore, the band gap can be obtained by extrapolation of the previous relation in the inset of Figure 1. The intercept of the tangent to the plot gives a good approximation of the band gap energy of direct band gap materials. The calculated energy band gap values are $\sim 3.7 \mathrm{eV}$ for $\mathrm{SnO}_{2}$ nanowires and $\sim 3.64 \mathrm{eV}$ for commercially bought $\mathrm{SnO}$ powder, respectively. These values are slightly larger than that of bulk $\mathrm{SnO}_{2}(3.62 \mathrm{eV})$ and might be due to the quantum size effect [26-28].
TABLE 1: Quantitative analysis of the $\mathrm{SnO}_{2}$ nanowires.

\begin{tabular}{lcc}
\hline Element & Atomic\% & Weight $\%$ \\
\hline $\mathrm{O}$ & $64.53-$ & $20.78-$ \\
$\mathrm{Sn}$ & $30.42 \pm 0.27$ & $72.68 \pm 0.64$ \\
$\mathrm{Cu}$ & $2.71 \pm 0.21$ & $3.47 \pm 0.27$ \\
$\mathrm{Zn}$ & $2.33 \pm 0.27$ & $3.07 \pm 0.36$ \\
\hline
\end{tabular}

Figure 2 shows the scanning electron microscopy (SEM) micrographs of Figure 2(a) commercially bought SnO powder and Figures 2(b) and 2(c) fluffy gray $\mathrm{SnO}_{2}$ product that was collected on the wall of the inner quartz tube after it was synthesized at a growth temperature of $1050^{\circ} \mathrm{C}$ for $30 \mathrm{~min}$. It is evident that the as-synthesized products are dominated by "wire-like" structures whose diameter varies from 50 to $200 \mathrm{~nm}$. The length of the wires ranges from several tens to several hundred micrometers. Figures 3(a) and 3(b) show high magnification images of the nanowires. It is observed that spherical particles are attached to the ends of the nanowires. Energy-dispersive X-ray spectroscopy (EDS) analysis (Figure 4 and Table 1) extracted at four different spots showed that the tip of the nanowires consists of tin $(\mathrm{Sn})$ and oxygen $(\mathrm{O})$ only. The $\mathrm{Cu}$ and $\mathrm{Zn}$ peaks present in the EDS spectra are from the brass stubs used in the sample preparation. The result reveals that the products are the coexistence of $\mathrm{Sn}$ and $\mathrm{O}$ with a molar ratio of $33.21: 66.64$, which is consistent with the composition of $\mathrm{SnO}_{2}$ and is in good agreement with the XRD results (Figure 5).

The X-ray diffraction analyses of the tin oxide precursor were carried out as shown in Figure 5(a). All the diffraction peaks can be attributed to the tetragonal tin oxide $(\mathrm{SnO})$ (JCPDS 006-0395), with lattice constants of $a=b=3.802 \AA$ and $c=4.836 \AA$. Figure $5(\mathrm{~b})$ shows the $\mathrm{X}$-ray diffraction pattern for the synthesized tin oxide nanowires and ribbons. From the diffraction patterns, the as-synthesized $\mathrm{SnO}_{2}$ nanowires have a good crystallinity with the tetragonal tin oxide $\mathrm{SnO}_{2}$ structure. The structure of the nanowires was further characterized by transmission electron microscopy and selected area electron diffraction (SAED) patterns. Figures 6(a) and 6(b) show a low and high magnification TEM image of a single $\mathrm{SnO}_{2}$ nanowire, respectively, with uniform diameter. It is evident that the diameter of nanowires/nanobelts varies from 50 to $200 \mathrm{~nm}$ with a few Sn droplets on the nanowires. The observed tip morphology on top of the $\mathrm{SnO}_{2}$ nanowires is consistent with the SEM analysis. The SAED pattern of the tip and the tail of the nanowires are shown in Figures 6(c) and 6(d), respectively. The patterns clearly confirm the polycrystalline nature of the nanowires. It should be pointed out that no metal catalyst was used during the growth of the nanowires. Therefore, based on these findings, we can conclude that the $\mathrm{SnO}_{2}$ nanowires follow the vapor liquid-solid (VLS) growth mechanism.

The growth mechanism of nanowires in thermal evaporation [29] can be explained by either vapour-liquid-solid (VLS) [30] and or vapour-solid (VS) [31]. Vapor-liquid-solid (VLS) mechanism is a catalyst-assisted growth process, where metal nanoclusters or nanoparticles are used as the nucleation seeds. These nucleation seeds determine the interfacial 


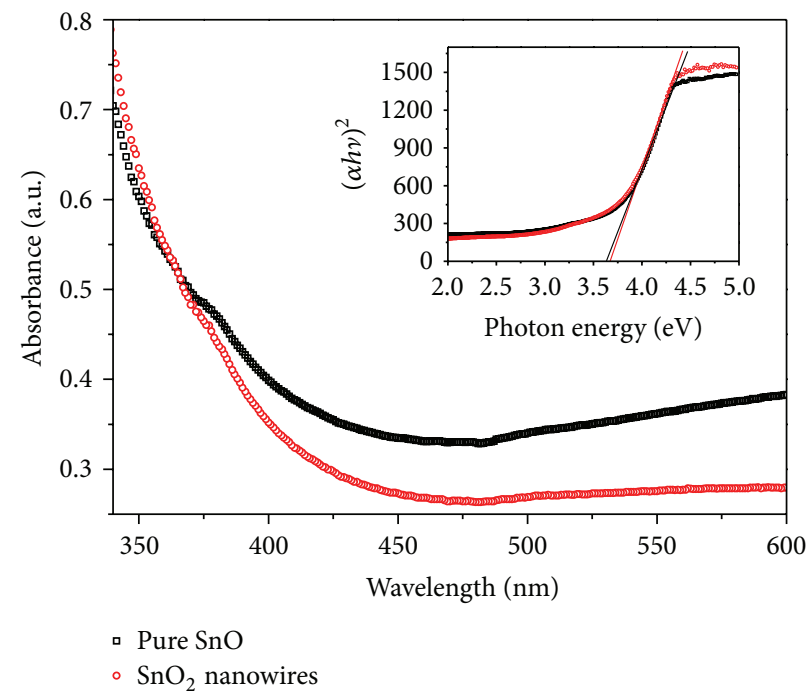

FIGURE 1: UV-visible absorption spectra of commercially bought $\mathrm{SnO}$ powder and $\mathrm{SnO}_{2}$ nanowires. The inset shows the $(\alpha h \nu)^{2}$ versus photon energy curve.

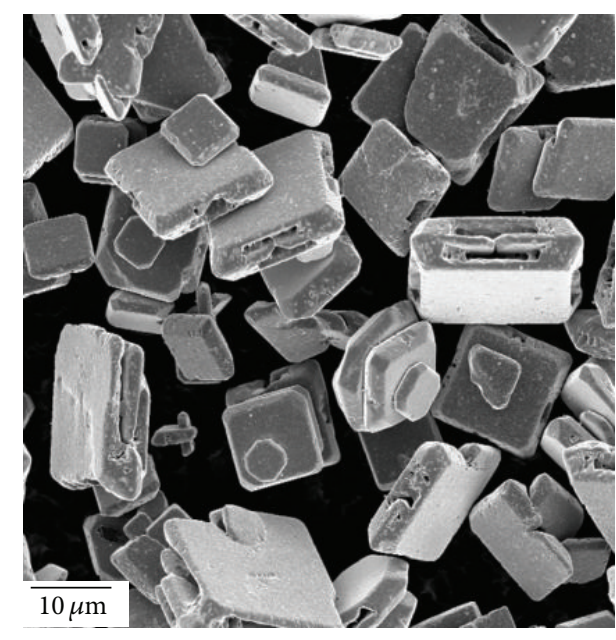

(a)

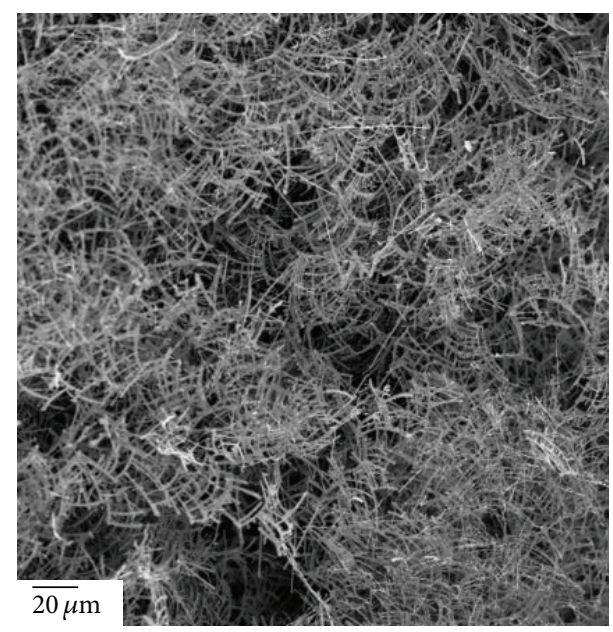

(b)

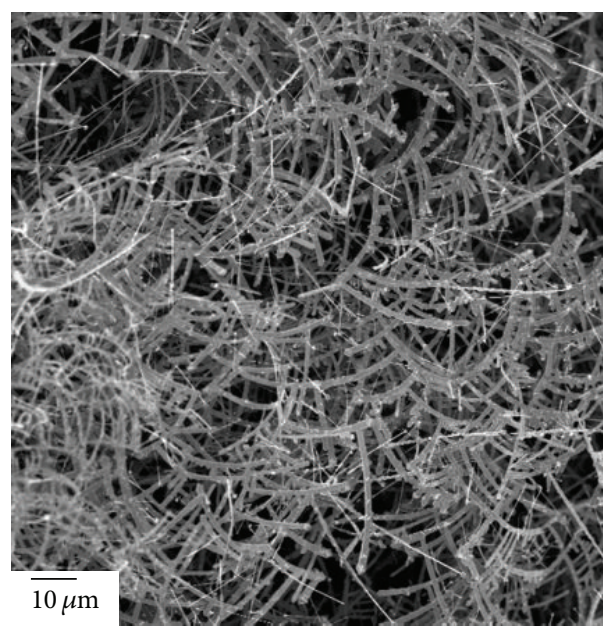

(c)

FIGURE 2: SEM micrographs of (a) pure commercially bought $\mathrm{SnO}$ powders and (b) and (c) $\mathrm{SnO}_{2}$ nanowire networks synthesized at $1050^{\circ} \mathrm{C}$ for $30 \mathrm{~min}$. 


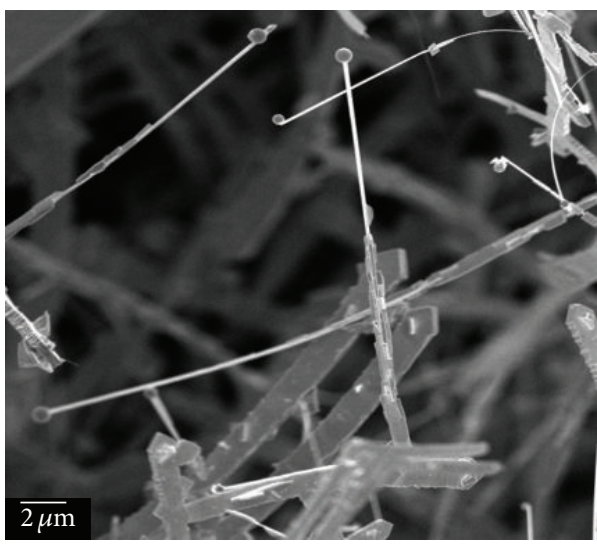

(a)

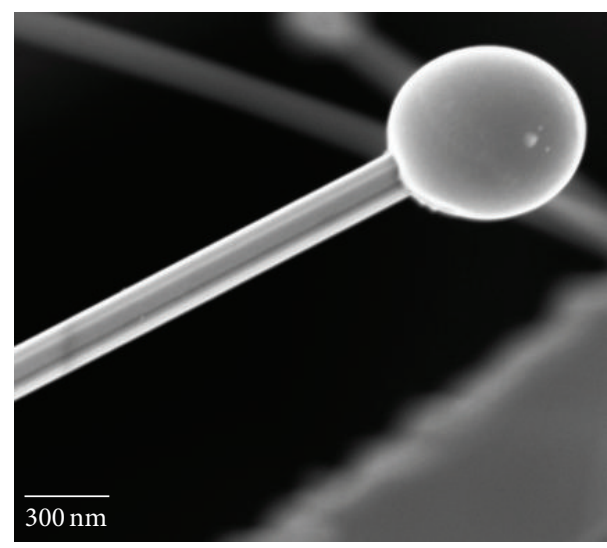

(b)

FIGURE 3: (a) SEM images of the synthesized $\mathrm{SnO}_{2}$ nanowires and (b) a high magnification image of a single nanowire with a tip.

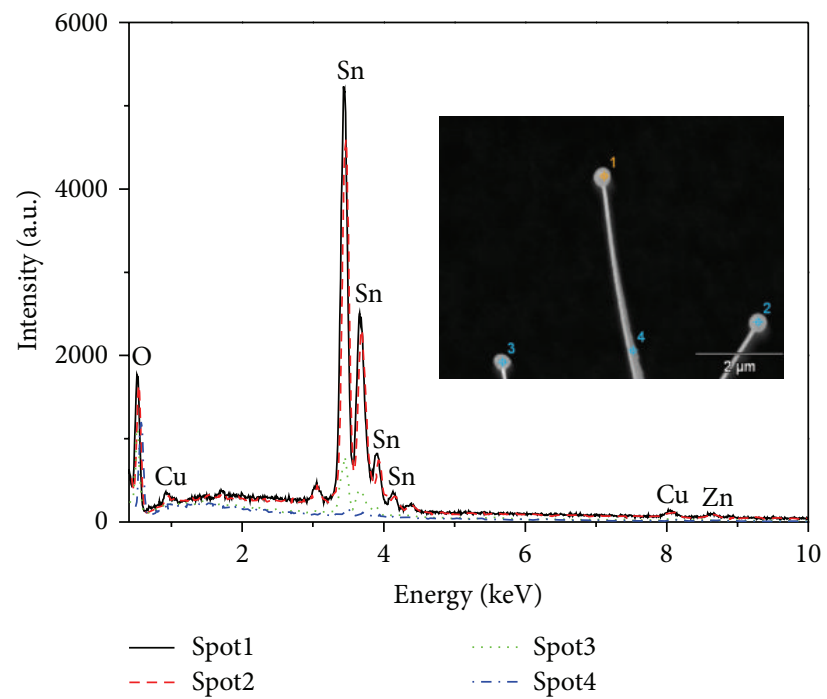

FIGURE 4: EDS spectra of four different spots of tin oxide nanowires. The inset shows the SEM images and the different spots analyzed.

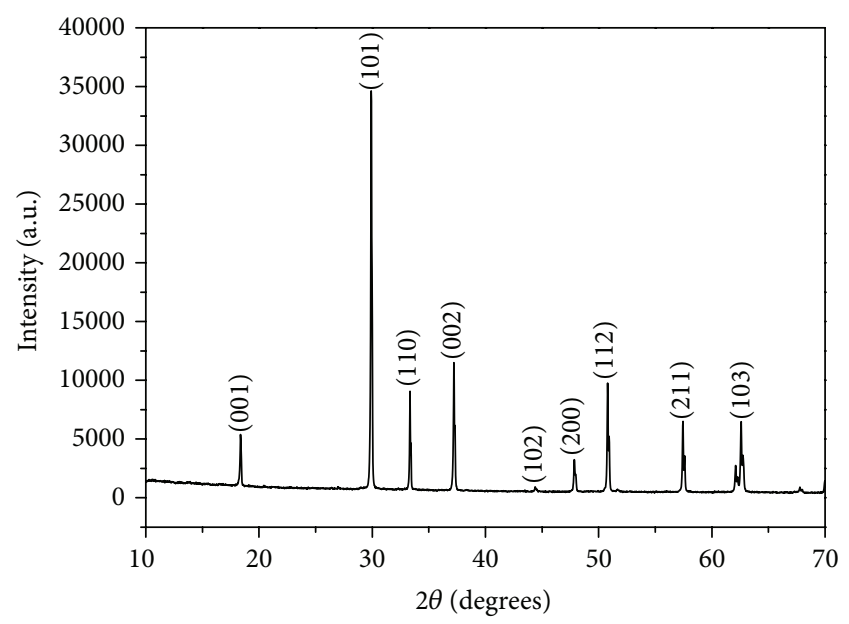

- Pure SnO

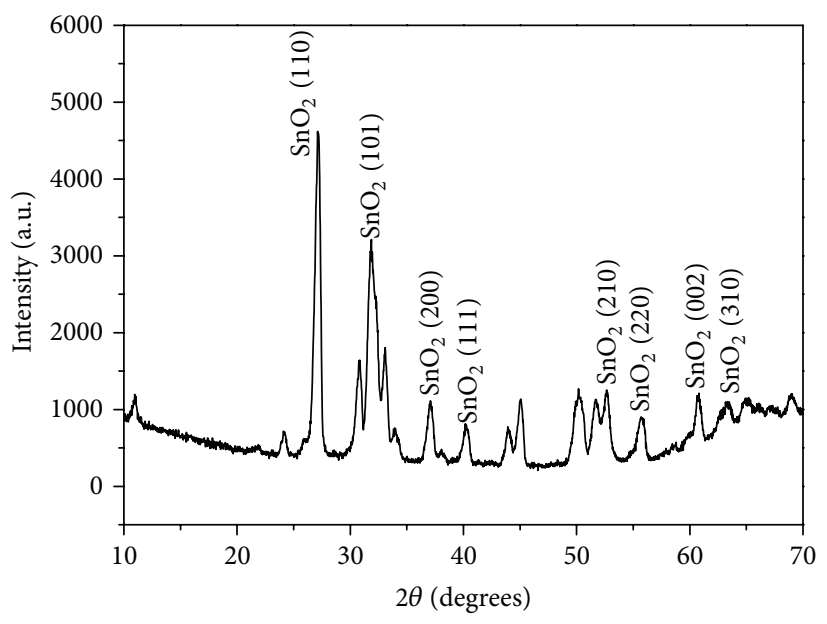

- $\mathrm{SnO}_{2}$ synthesized at $1050^{\circ} \mathrm{C}$

(b)

Figure 5: X-ray diffraction patterns of (a) pure $\mathrm{SnO}$ and (b) the as-synthesized $\mathrm{SnO}_{2}$ nanowires at a growth temperature of $1050^{\circ} \mathrm{C}$ for 30 min. 


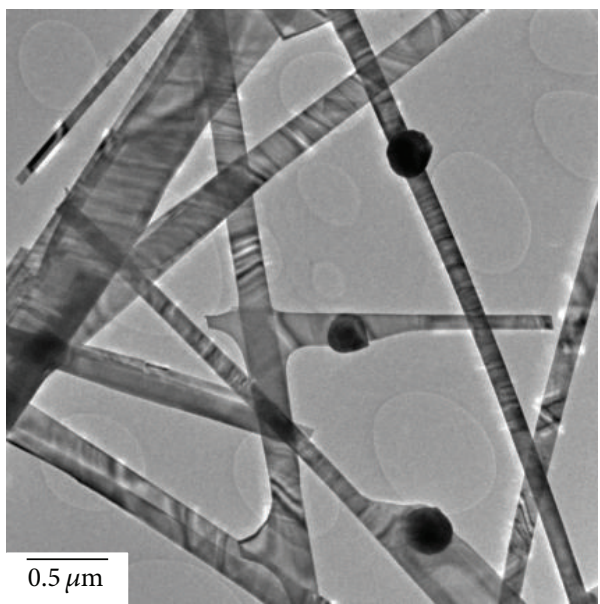

(a)

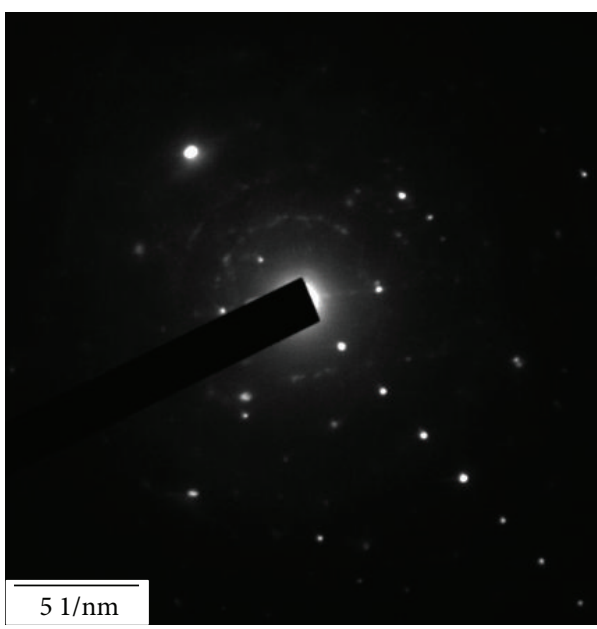

(c)

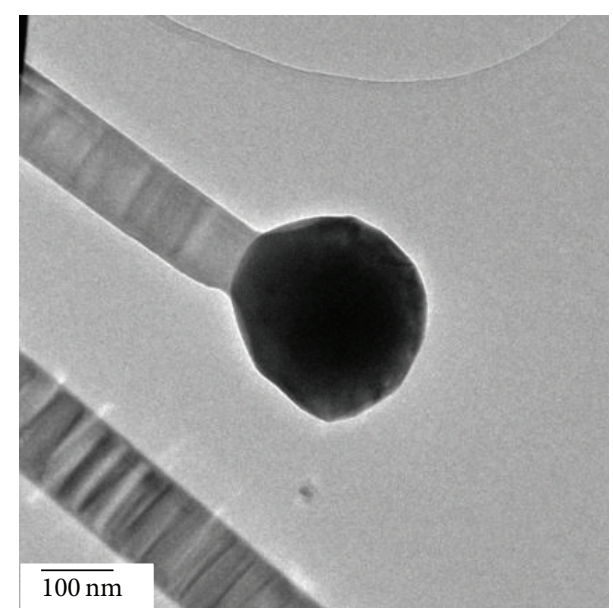

(b)

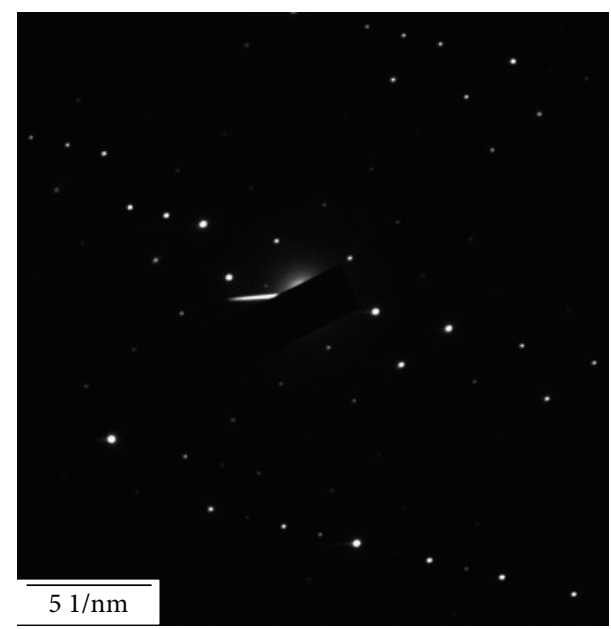

(d)

FIGURE 6: (a) and (b) Bright-field TEM images of $\mathrm{SnO}_{2}$ nanowires and the corresponding diffraction patterns of (c) tip and (d) tail of the nanowires.

energy, growth direction, and diameter of the final 1D metal oxide nanostructures. Briefly, the following chemical reaction will take place during the thermal evaporation process [29]:

$$
2 \mathrm{SnO}(\mathrm{g}) \longrightarrow \mathrm{Sn}(\mathrm{l})+\mathrm{SnO}_{2}(\mathrm{~s}) \text {. }
$$

It is believed that tin oxide ( $\mathrm{SnO}$ ) vapor will be transferred by the argon gas (Ar) or is naturally spread out by thermal diffusion to the deposition area. Because $\mathrm{SnO}$ is metastable, it will decompose into $\mathrm{Sn}$ and $\mathrm{SnO}_{2}$ above $600^{\circ} \mathrm{C}$, forming $\mathrm{Sn}$ droplets as shown from the previous equation. According to this mechanism, a metal catalyst is needed for Sn-metal alloy droplets by the reaction with the metal catalyst particles. At the same time, these droplets can provide the energetically favored sites for adsorption of $\mathrm{SnO}$ vapor. Subsequently, the decomposition of $\mathrm{SnO}$ will result in the precipitation of $\mathrm{SnO}_{2}$, and this leads to the formation of $\mathrm{SnO}_{2}$ nanostructures [32]. However, in this process, no catalyst was used, and therefore the growth of the nanowires is not consistent with the VLS model but governed by the VS mechanism. Therefore, the nanonuclei necessary for the VLS growth of nanowires, which used to be obtained by adding an adscititious metal catalyst, can also be created through internal chemical reactions of precursors which are considered to be a self-catalytic growth, which is in good agreement with the results obtained by the EDS analysis.

\section{Conclusions}

$\mathrm{SnO}_{2}$ nanowires have been successfully synthesized using a quartz tube-based CVD reactor at a growth temperature of $1050^{\circ} \mathrm{C}$ for 30 minutes. The microstructures and surface compositions of the nanowires were characterized by SEMEDS, XRD, and TEM. The SEM micrographs revealed "woollike" structures with a network of nanowires, ribbons, and belts. The nanowires follow the vapor-liquid-solid growth mechanism which is evident because of the liquid droplets on the tip of the nanowires. They serve as transporting medium as the nanowires develop as a result of the precipitation process. No metal catalyst was used in the synthesis of these nano wires which proves that the tin oxide is selfcatalytic during the synthesis process. EDX analysis showed 
that the samples are purely $\mathrm{Sn}$ and $\mathrm{O}$ with a $1: 2$ weight ratio. Nanowires have diameters in the range of $50-200 \mathrm{~nm}$ and length $10-100 \mu \mathrm{m}$. X-ray diffraction analysis confirmed that the as-synthesized materials are highly crystalline. The band gap value of the $\mathrm{SnO}_{2}$ nanowires obtained by UV-vis was around $3.7 \mathrm{eV}$.

\section{Acknowledgments}

The authors would like to acknowledge the financial support of the Council for Scientific and Industrial Research (CSIR), South Africa, (Project no.: HGER27S) and the Department of Science and Technology.

\section{References}

[1] S. Y. Li, C. Y. Lee, and T. Y. Tseng, "Copper-catalyzed ZnO nanowires on silicon (1 000$)$ grown by vapor-liquid-solid process," Journal of Crystal Growth, vol. 247, no. 3-4, pp. 357-362, 2003.

[2] J. X. Wang, D. F. Liu, X. Q. Yan et al., "Growth of $\mathrm{SnO}_{2}$ nanowires with uniform branched structures," Solid State Communications, vol. 130, no. 1-2, pp. 89-94, 2004.

[3] Z. W. Pan, Z. R. Dai, L. Xu, S. T. Lee, and Z. L. Wang, "Temperature-controlled growth of silicon-based nanostructures by thermal evaporation of SiO powders," Journal of Physical Chemistry B, vol. 105, no. 13, pp. 2507-2514, 2001.

[4] K. D. Schierbaum, U. Weimar, and W. Gopel, "Schottky-barrier and conductivity gas sensors based upon $\mathrm{Pd} / \mathrm{SnO}_{2}$ and $\mathrm{Pt} /$ $\mathrm{TiO}_{2}$," Sensors and Actuators B, vol. 4, no. 1-2, pp. 87-94, 1992.

[5] D. E. Williams, "Semiconducting oxides as gas-sensitive resistors," Sensors and Actuators B, vol. 57, no. 1-3, pp. 1-16, 1999.

[6] W. Fliegel, G. Behr, J. Werner, and G. Krabbes, "Preparation, development of microstructure, electrical and gas-sensitive properties of pure and doped $\mathrm{SnO}_{2}$ powders," Sensors and Actuators $B$, vol. 19, no. 1-3, pp. 474-477, 1994.

[7] G. Korotcenkov, "Metal oxides for solid-state gas sensors: what determines our choice?" Materials Science and Engineering: B, vol. 139, no. 1, pp. 1-23, 2007.

[8] G. Korotcenkov, V. Brynzari, and S. Dmitriev, " $\mathrm{SnO}_{2}$ films for thin film gas sensor design," Materials Science and Engineering: B, vol. 63, no. 3, pp. 195-204, 1999.

[9] N. Yamazoe, Y. Kurokawa, and T. Seiyama, "Effects of additives on semiconductor gas sensors," Sensors and Actuators, vol. 4, pp. 283-289, 1983.

[10] G. Zhang and M. Liu, "Effect of particle size and dopant on properties of $\mathrm{SnO}_{2}$-based gas sensors," Sensors and Actuators B, vol. 69, no. 1, pp. 144-152, 2000.

[11] K. J. Albert, N. S. Lewis, C. L. Schauer et al., "Cross-reactive chemical sensor arrays," Chemical Reviews, vol. 100, no. 7, pp. 2595-2626, 2000.

[12] M. Meyyappan and M. S. Sunkara, Inorganic Nanowires, CRC, Boca Raton, Fla, USA, 2009.

[13] Z. Ying, Q. Wan, Z. T. Song, and S. L. Feng, " $\mathrm{SnO}_{2}$ nanowhiskers and their ethanol sensing characteristics," Nanotechnology, vol. 15, no. 11, pp. 1682-1684, 2004.

[14] V. V. Sysoev, B. K. Button, K. Wepsiec, S. Dmitriev, and A. Kolmakov, "Toward the nanoscopic "electronic nose": hydrogen vs carbon monoxide discrimination with an array of individual metal oxide nano- and mesowire sensors," Nano Letters, vol. 6, no. 8, pp. 1584-1588, 2006.

[15] J. G. Lu, P. Chang, and Z. Fan, "Quasi-one-dimensional metal oxide materials-synthesis, properties and applications," Materials Science and Engineering: $R$, vol. 52, no. 1-3, pp. 49-91, 2006.

[16] N.-L. Wu, S.-Y. Wang, and I. A. Rusakova, "Inhibition of crystallite growth in the sol-gel synthesis of nanocrystalline metal oxides," Science, vol. 285, no. 5432, pp. 1375-1377, 1999.

[17] Y. Wang, X. Jiang, and Y. Xia, "A solution-phase, precursor route to polycrystalline $\mathrm{SnO}_{2}$ nanowires that can be used for gas sensing under ambient conditions," Journal of the American Chemical Society, vol. 125, no. 52, pp. 16176-16177, 2003.

[18] M. Yuasa, T. Masaki, T. Kida, K. Shimanoe, and N. Yamazoe, "Nano-sized PdO loaded $\mathrm{SnO}_{2}$ nanoparticles by reverse micelle method for highly sensitive CO gas sensor," Sensors and Actuators B, vol. 136, no. 1, pp. 99-104, 2009.

[19] M. H. Huang, Y. Wu, H. Feick, N. Tran, E. Weber, and P. Yang, "Catalytic growth of zinc oxide nanowires by vapor transport," Advanced Materials, vol. 13, no. 2, pp. 113-116, 2001.

[20] J. D. Holmes, K. P. Johnston, R. C. Doty, and B. A. Korgel, "Control of thickness and orientation of solution-grown silicon nanowires," Science, vol. 287, no. 5457, pp. 1471-1473, 2000.

[21] J. S. Jeong, J. Y. Lee, C. J. Lee, S. J. An, and G. C. Yi, "Synthesis and characterization of high-quality $\operatorname{In}_{2} \mathrm{O}_{3}$ nanobelts via catalystfree growth using a simple physical vapor deposition at low temperature," Chemical Physics Letters, vol. 384, no. 4-6, pp. 246-250, 2004.

[22] M. J. Zheng, L. D. Zhang, G. H. Li, X. Y. Zhang, and X. F. Wang, "Ordered indium-oxide nanowire arrays and their photoluminescence properties," Applied Physics Letters, vol. 79, p. 839, 2001.

[23] N. G. Patel, K. K. Makhija, C. J. Panchal, D. B. Dave, and V. S. Vaishnav, "Fabrication of carbon tetrachloride gas sensors using indium tin oxide thin films," Sensors and Actuators B, vol. 23, no. 1, pp. 49-53, 1995.

[24] D. Frohlich and R. Kenklies, "Band-gap assignment in $\mathrm{SnO}_{2}$ by two-photon spectroscopy," Physical Review Letters, vol. 41, no. 25, pp. 1750-1751, 1978.

[25] G. Mill, Z. G. Li, and D. Merisel, "Photochemistry and spectroscopy of colloidal arsenic sesquisulfide," The Journal of Physical Chemistry, vol. 92, no. 3, pp. 822-828, 1988.

[26] S. Luo, P. K. Chu, W. Liu, M. Zhang, and C. Lin, "Origin of low-temperature photoluminescence from $\mathrm{SnO}_{2}$ nanowires fabricated by thermal evaporation and annealed in different ambients," Applied Physics Letters, vol. 88, Article ID 183112, 3 pages, 2006.

[27] A. L. Efros and A. L. Efros, "Interband absorption of light in a semiconductor sphere," Soviet Physics: Semiconductors, vol. 16, pp. 772-775, 1982.

[28] L. Brus, "A simple model for the ionization potential, electron affinity, and aqueous redox potentials of small semiconductor crystallites," Journal of Chemical Physics, vol. 79, no. 11, p. 5566, 1983.

[29] B. Wang, Y. H. Yang, C. X. Wang, and G. W. Yang, "Nanostructures and self-catalyzed growth of $\mathrm{SnO}_{2}$," Journal of Applied Physics, vol. 98, no. 7, Article ID 073520, 5 pages, 2005.

[30] R. S. Wagner and W. C. Ellis, "Vapor-liquid-solid mechanism of single crystal growth," Applied Physics Letters, vol. 4, no. 5, p. 89, 1964. 
[31] G. Gundiah, A. Govindaraj, and C. N. R. Rao, "Nanowires, nanobelts and related nanostructures of $\mathrm{Ga}_{2} \mathrm{O}_{3}$," Chemical Physics Letters, vol. 351, no. 3-4, pp. 189-194, 2002.

[32] A. Kolmakov, Y. Zhang, G. Cheng, and M. Moskovits, "Detection of $\mathrm{CO}$ and $\mathrm{O}_{2}$ using tin oxide nanowire sensors," Advanced Materials, vol. 15, no. 12, pp. 997-1000, 2003. 

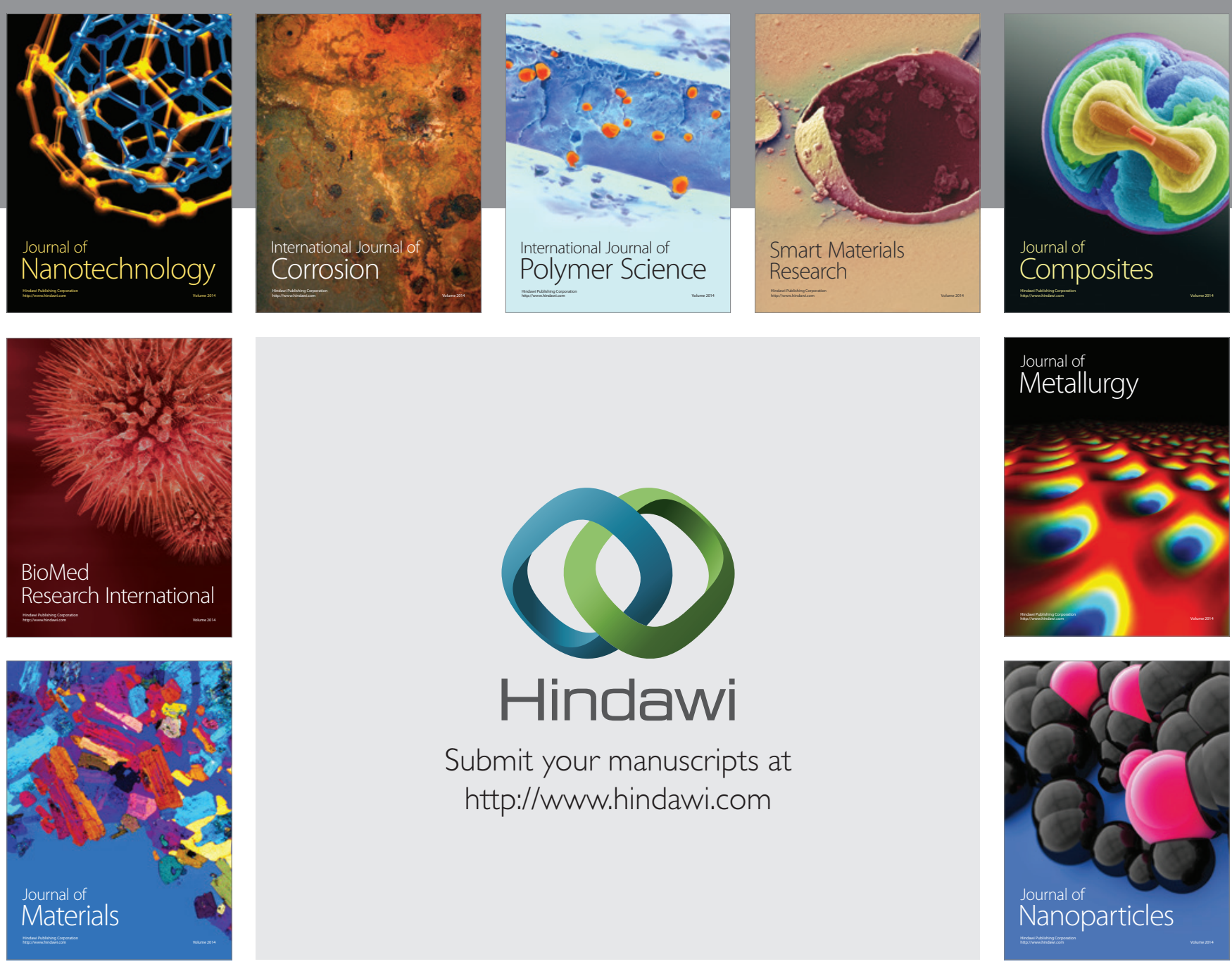

Submit your manuscripts at http://www.hindawi.com
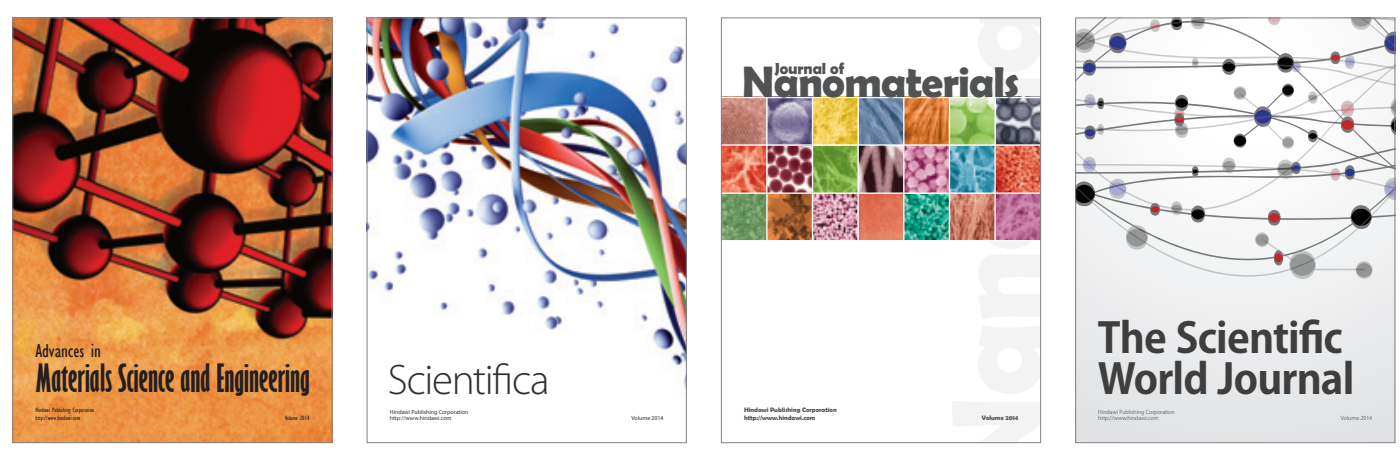

\section{The Scientific World Journal}
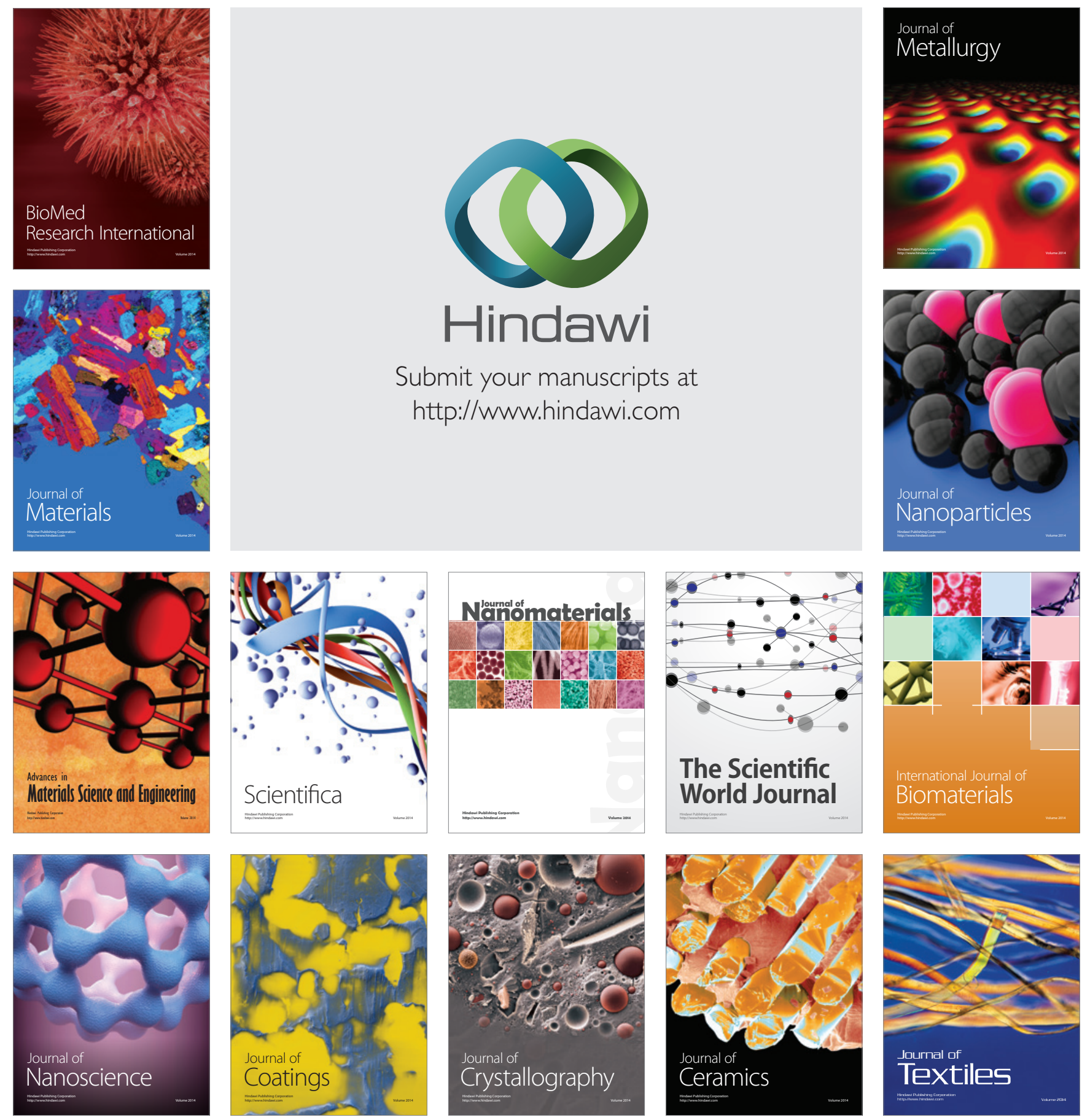